\title{
Unique observatories for sea science and particle astrophysics: The EMSO-Antares and EMSO-Western Ionian nodes in the Mediterranean Sea
}

\author{
Dominique Lefevre ${ }^{1,{ }^{*}}$, Bruno Zakardkjian ${ }^{1}$ and Daniele Embarcio $^{2}$ for the KM3NeT, ANTARES \\ and EMSO-ERIC collaborations ${ }^{3}$ \\ ${ }^{1}$ Aix Marseille Univ, Université de Toulon, CNRS, IRD, MIO UM 110, 13288, Marseille, France \\ 2Istituto Nazionale di Geofisica e Vulcanologia, via di Vigna Murata 605, Roma, Italy \\ ${ }^{3}$ ANTARES. http://antares.in2p3.fr, KM3NeT. https://km3net.org, EMSO-ERIC. www.emso-eu.org
}

\begin{abstract}
We describe two of the nodes of the European Multidisciplinary Seafloor and water-column Observatory (EMSO) which are closely connected to the two sites of the KM3NeT infrastructure: EMSOAntares in the West Ligurian sea and the EMSO Western Ionian Sea Node. We present the general characteristics and objectives of both nodes and illustrate their capabilities with some illustrative results.
\end{abstract}

\section{Introduction}

The European Multidisciplinary Seafloor and water-column Observatory (EMSO) is a large-scale distributed Research Infrastructure for ocean observation, enabling real-time interactive long-term monitoring of ocean processes including natural hazards, climate change, and marine ecosystems. EMSO nodes have been deployed at key sites in European seas, starting from the Arctic, through the Atlantic and Mediterranean, to the Black Sea (Fig. 1) in order to address topics of regional importance: the biodiversity of mid ocean hot

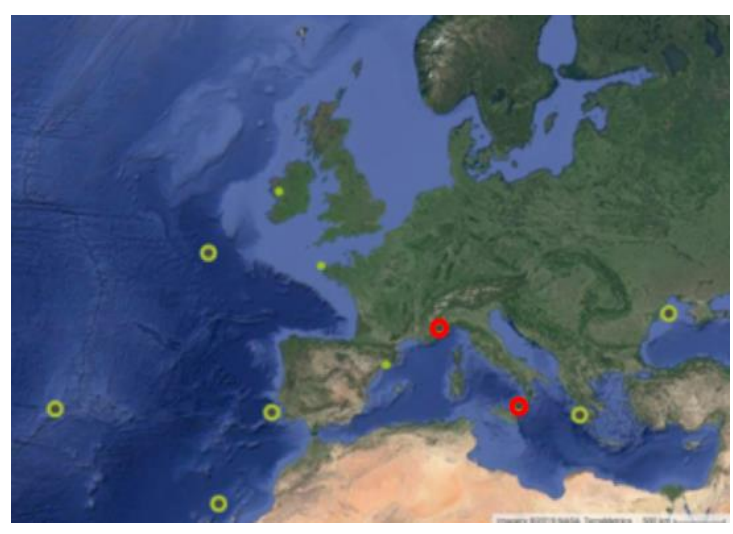
vents in the Azores region, the rapidly changing environmental conditions affecting the geosphere and biosphere of the Arctic, deep-water ventilation in the eastern Mediterranean, the active seismicity and the associated geohazards of the Anatolian region.

Figure 1. Map of the 11 EMSO Regional Facilities. Dots mark test sites. The EMSO ANTARES and Western ionian nodes are in red.

*e-mail: dominique.lefevre@mio.osupytheas.fr 
EMSO has been recently integrated as an European Research Infrastructure Consortium (ERIC) to unify the regional observatories into a common infrastructure with the following missions: to implement more sensor packages to collect synoptic data series on oceanographic features of more than regional interest; to ensure maintenance of this infrastructure over a longer time-span than possible by national funding programs; to bring these data together in a uniform format accessible to a large and diverse group of users, from scientists and industries to institutions and policy makers.

Among the eleven EMSO observation sites, two are strongly linked with KM3NeT (Kilometre-Cube Underwater Neutrino Telescope), a large-scale European research infrastructure devoted to fundamental astrophysics research. Those are the EMSO-Catania node in the Western Ionian Sea and the EMSO-ANTARES node in the Western Ligurian Sea. They benefit from the deep sea cabled installations and logistics facilities of KM3NeT to set up unique real-time multidisciplinary ocean and environmental observatories addressing seismology, geomagnetism, physical and biogeochemical oceanography and hydro-acoustic and bio-acoustic sciences. The following is a synthetic description of the scientific objectives, infrastructures, related instrumentation for both nodes with some illustrations of currently acquired data.

\section{EMSO Western Ionian node in the Western Ionian Sea}

The Western Ionian Sea area is prone to numerous natural hazard issues due to high seismicity in an area of collision between African and European plates and the presence of the Mount Etna volcano whose roots possibly sink down to seafloor. Indeed, the region experienced large historical earthquakes, and some of the strongest earthquakes (the most recent in 1908) caused also very intense tsunami wave. The Ionian Sea is also a key site for the Mediterranean Sea circulation, as it acts as a collector for superficial Modified Atlantic Water (MAW) coming from the western Mediterranean basin via the Sicily Straits (flowing between 50 and $150 \mathrm{~m}$ depth), for the Levantine Intermediate Water (LIW) spreading from the eastern basin (between 200 and 600m depth), and for deeper Adriatic Denser Water (ADW) diffusing through the Otranto Strait (between 1000 and $1500 \mathrm{~m}$ ) [2-4]. Last, it is a key area for the monitoring of the marine mammal's population trends in relation to climate changes and human impacts.

The scientific objectives of this EMSO node include geo hazards assessment with realtime monitoring of earthquakes and tsunamis, monitoring of physical oceanographic parameters and water mass properties at the seafloor and along the water column, time variations of terrestrial potential fields and electrical properties, marine acoustic noise characterisation and bio-acoustic tracking and rheological properties of solid matter. The Catania site will host the EGIM (EMSO generic Instrument Modules) and the NEMO-SN1 observatory [5].

The two observatories host instrumentation for temperature, pressure, conductivity, dissolved $\mathrm{O}_{2}$, turbidity, ocean currents, acoustics, magnetic field, and seismicity. An underwater cable runs on the seafloor from Catania harbour and splits in two branches at about $20 \mathrm{~km}$ off the Eastern Sicily coasts and at about $2100 \mathrm{~m}$ depth. The North branch hosts the geophysical and oceanographic station NEMO-SN1, managed by INGV, and the South branch hosts the acoustic station OvDE, managed by INFN (Fig. 2) [4]. In the framework of neutrino astrophysics, and in connection to KM3NeT, the primary goal of the OvDE observatory is the characterisation of the ambient noise to discriminate acoustic 
background (e.g. surface waves, biological sources, ships) from the bipolar $(10-40 \mathrm{kHz})$ signature of high-energy cosmic neutrinos interacting with seawater [1]. Acoustic detectors are used for sea noise monitoring, considering that acoustic pollution affects the good environmental status of the sea. Underwater noise, for example, could interfere with the main communication channel for several marine species, thus altering the ecological equilibrium in the area.

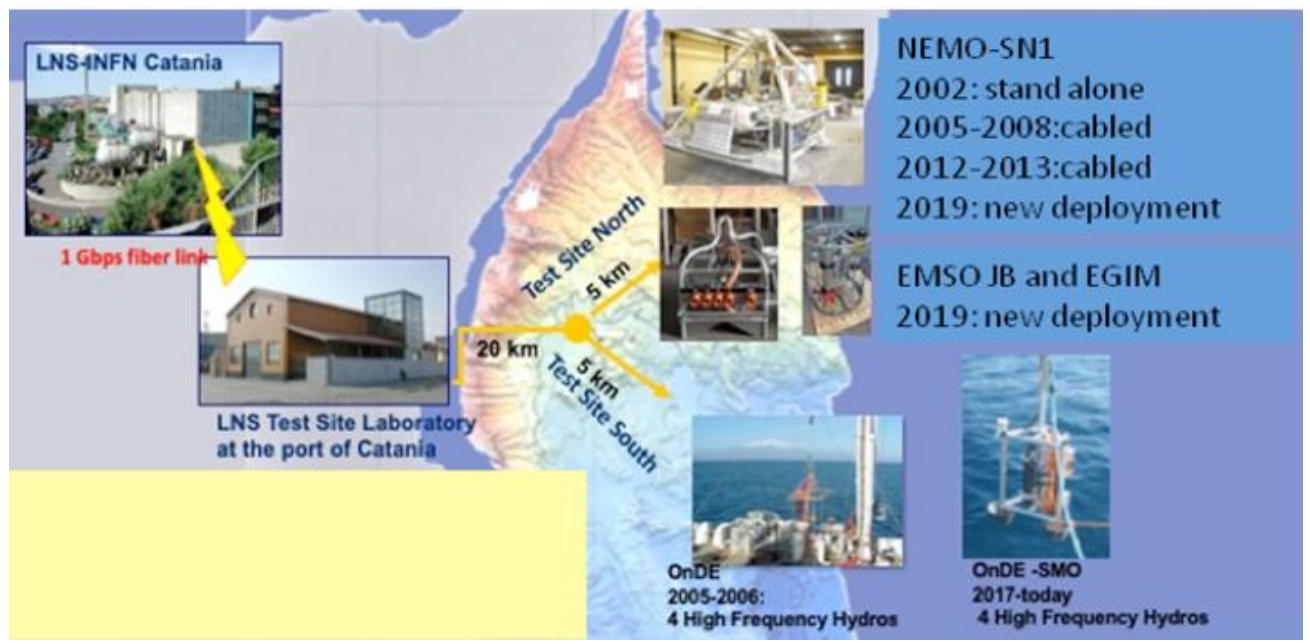

Figure 2. Configuration of the subsea infrastructure offshore Catania, where the EMSO Western Ionian Node is located (North Branch). Running and foreseen experiments are indicated.

The hydrophones used both in NEMO-SN1 and in OvDE cover a larger bandwidth from tens of $\mathrm{Hz}$ to $\approx 70 \mathrm{kHz}$, allowing detection of different marine mammals from fin whales (tens $\mathrm{Hz}$ ) to Cuvier's beaked whales (more than $50 \mathrm{kHz}$. These studies have already contributed to individuate an unprecedented and huge number of sperm whales, up to then given for disappeared, with daily detection [7] in the area.
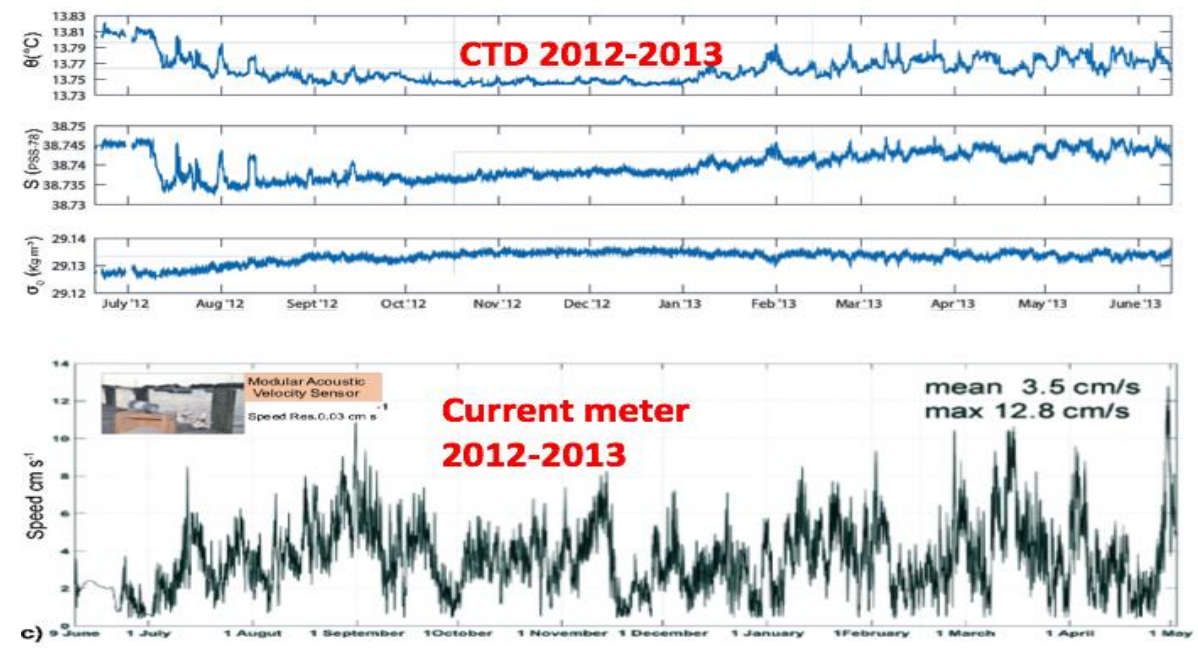

Figure 3. Temperature, salinity, density and current total velocity measured between June 2012 and July 2013 at $2.1 \mathrm{~km}$ depth by the NEMO-SN1 multidisciplinary geophysical unit, http://www.moist.it 
As another example for the data taken, Figure 3 shows water parameters measured between June 2012 and June 2013. It demonstrates that it is possible to monitor deep and high frequency events of hydrological changes and joint deep ocean current variability. Such an infrastructure will allow to detect intense changes in the main water mass constituents like those already observed in the early 1990s (the Eastern Mediterranean Transient event), that conditioned, for a long time, the deep dynamics of the Ionian Sea and have had implications for the whole Mediterranean circulation [8-10].

A mooring system, managed by CNR, was also recently set up near the North branch in autonomous mode to monitor seawater column properties.

\section{The EMSO-ANTARES node in the Western Ligurian Sea}

EMSO-ANTARES is one site among three of the EMSO Ligurian Sea Regional Facility (Fig. 5). The two eastern sites are not described here. EMSO-ANTARES in the Western Ligurian site was initially hosted by the cabled infrastructure of ANTARES, the KM3NeT predecessor, and rested on a sea floor current-meter and short mooring lines instrumented with CTD and current-meters at depths of 2000-2400 m. The site is currently being upgraded in parallel to set up the next generation deep-sea neutrino telescope KM3NeTORCA (Oscillation Research with Cosmics in the Abyss), in the framework of the MEUST project (INSU and $\mathrm{IN}_{2} \mathrm{P}_{3}$, CNRS institutes, Universities of Aix-Marseille and Toulon and IFREMER). It now mainly rests on the ALBATROSS (Autonomous Line with a Broad Acoustic Transmission for Research in Oceanography and Sea Sciences) instrumented line that is deployed in the vicinity of the MII Instrumentation module [11]. The ALBATROSS line consists of two $1000 \mathrm{~m}$ long inductive cables connected to an embarked computer through an inductive modem. The line is instrumented with ten CTD and five currentmeters, allowing a more extended coverage of the water column (500 $\mathrm{m}$ to the bottom). Every 30 minutes, data from the instruments along the line are collected by the computer. A daily file is then sent to the interface module of the MII using acoustic data transmission, and from there to shore through the cable network. Presently data include pressure, temperature, conductivity, dissolved oxygen, suspended matter, current (velocity and direction), but the ALBATROSS mooring line is open to the community and it is available to host old/new or emerging sensors.

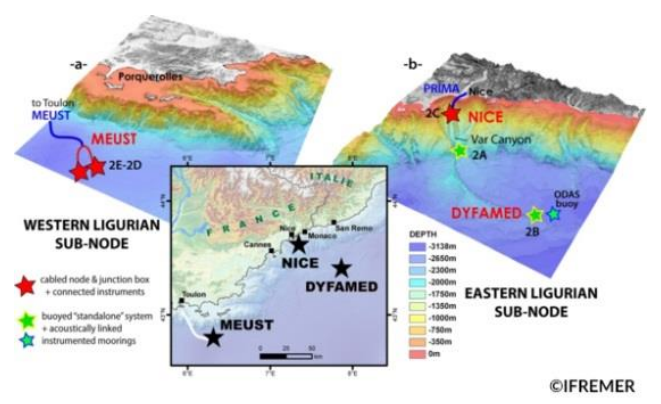

CIFREMER

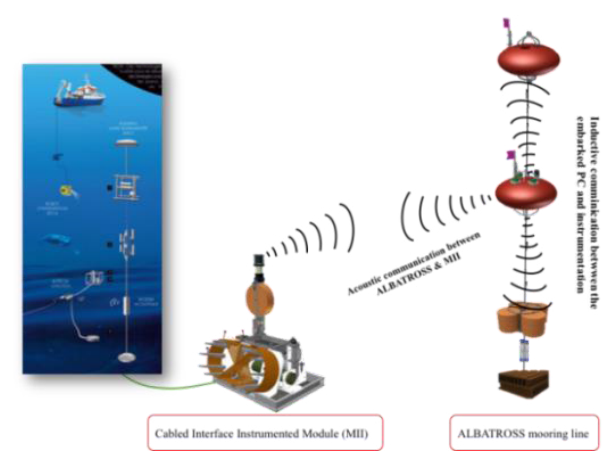

Cabled Interface linstrumented Module (MII)

Figure 4. Left, locations of the EMSO Ligurian node with its 3 sites: Nice airport site, open sea DYFAMED and EMSO-ANTARES (referred as MEUST in this representation); Right, artistic representation of the EMSO- $\mathrm{KM}_{3} \mathrm{NeT}$ deep-sea multidisciplinary observatory in the Western Ligurian Sea (C M. Destelle) and deployed infrastructure on node \#1: ALBATROSS Mooring Line and Interfaced Instrumented Module. 


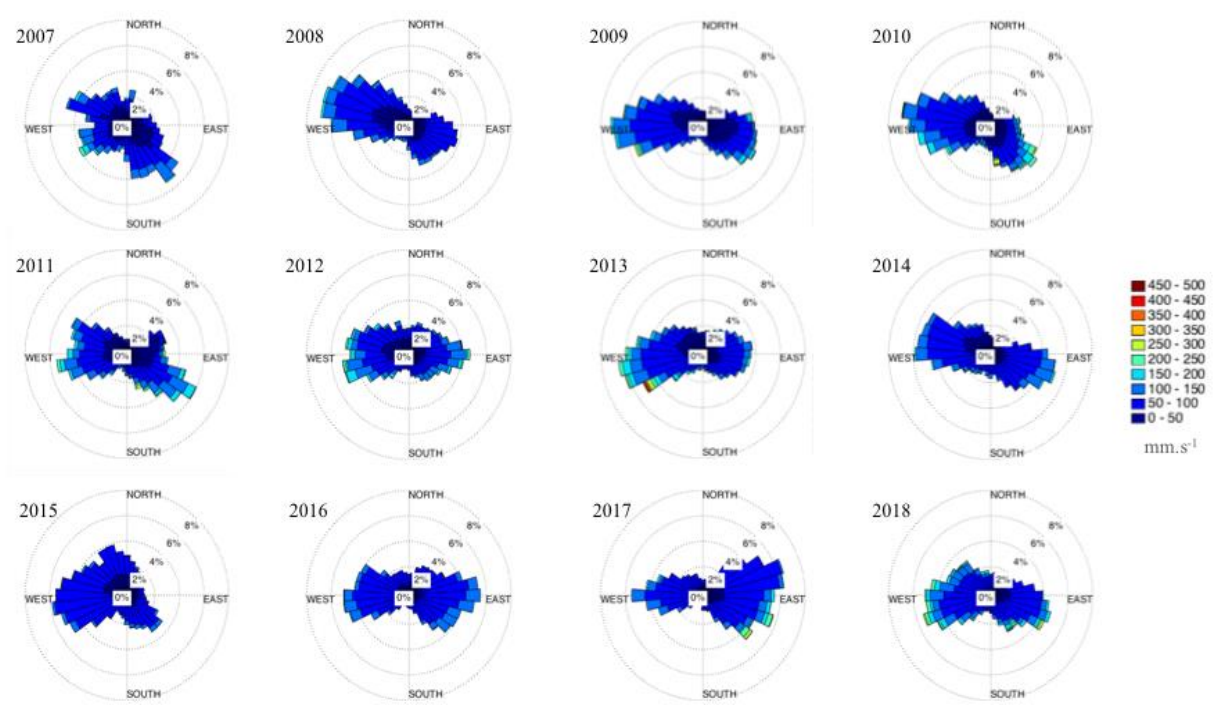

Figure 5. Current distribution for the water column 2000-2400 $\mathrm{m}$ at the EMSO ANTARES site for the period 2007-2018.

This variability is mostly related to barotropic instabilities of the NC, but a part of it may also come from remote effects of deep-water convection and formation of deep waters in the Gulf of Lion, a major oceanic process for the entire Western Mediterranean Sea. During years of intense deep convection, the newly formed deep water is spreading across the basin, affecting the bathypelagic ecosystem. Photomultipliers deployed, on the Neutrino telescope, allow the measurements of bioluminescence emitted mostly by in situ prokaryotes organisms. It has been demonstrated that the arrival of the newly formed deep waters at the EMSO-ANTARES site can significantly enhance the bioluminescent counts (Fig.6 left) suggesting a significant modification to the prokaryotic biomass and activity [13].

Likewise, the newly formed deep-water masses are refuelled in $\left[\mathrm{O}_{2}\right]$ during some winters as it is shown on Fig. 6 right. Also, it is worth noting that trends of dissolved oxygen [ $\mathrm{O}_{2}$ ] at 2300m (in 2 parts 2007-2010 and 2013-2015) $\mathrm{m}$ and $2000 \mathrm{~m}$ (2009-2016)

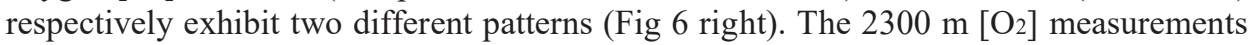
display a decreasing trend over time with a strong increasing event during the 2012-2013 winter [14]. The decrease is related to deep water in situ biological remineralisation as observed in other oceans [15] while the increased magnitude is related to the volume of newly formed deep water spreading across the basin. The $2000 \mathrm{~m}\left[\mathrm{O}_{2}\right]$ trend, at the contrary, is displaying no decrease with time on the pluri-annual scale but exhibit the same winter events related to deep water formation. This discrepancy in pluri-annual trends between $2000 \mathrm{~m}$ and $2300 \mathrm{~m}$, is related to different behaviour of the ecosystem and degree of fertilisation depending on the renewal of deep-water masses.

\section{Conclusions}

The two described EMSO related projects show how the synergy between astrophysicists, focused on neutrino research, and oceanographers, geophysicists and biologists, which need to follow continuously the water column and the deep sea floor, may help to build appropriate tools to monitor and understand either climate change effect on deep ecosystem 
evolution than geo-seismic hazards - both issues that are of premium socio-economic and population safety interests. The precious time series that such infrastructures provide are still on going, as well as their scientific exploitation, but the qualification of the data is a key process to interpret the trends they can reveal.
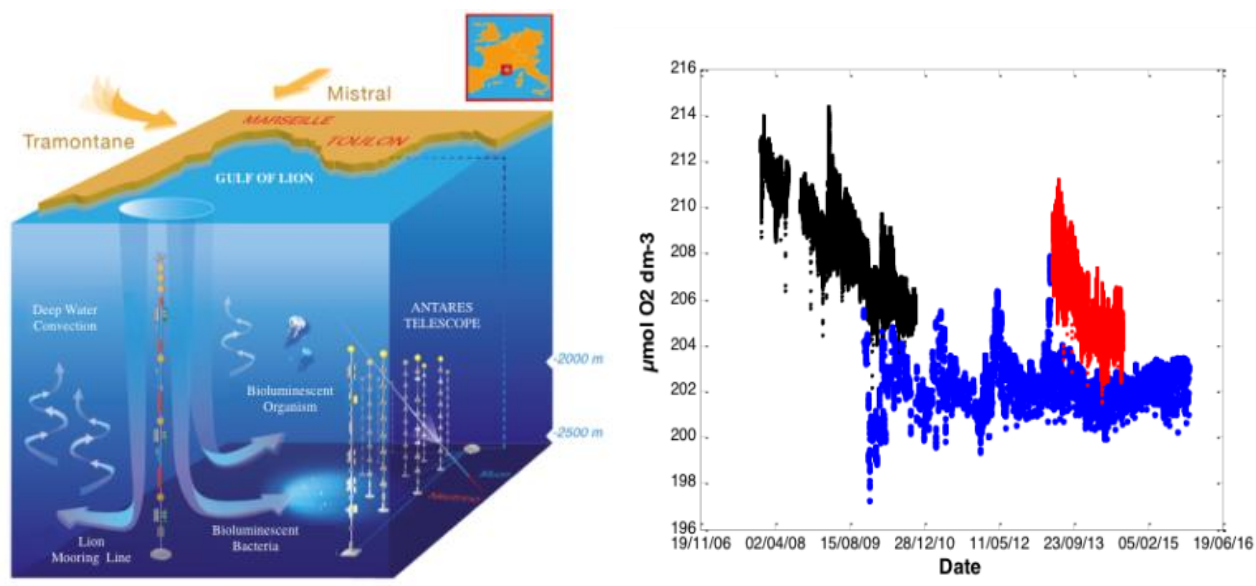

Figure 6. Left: Deep water formation and increase of biological/bioluminescence activity in the deep Sea. Right: Dissolved oxygen trend at $2300 \mathrm{~m}$ (black and red trends) exhibiting pluriannual decrease trend and a sudden increase in 2013 following deep water formation during the 2012-2013 winter; the same at $2000 \mathrm{~m}$ (blue points) is almost stable through time, showing only short-term regular events.

Acknowledements: The authors thank their colleagues from the EMSO-ERIC, ANTARES and KM3NeT Collaborations for supplying material: C.Gojak, C.Tamburini, K.Mahiouz, K.Bernardet, Z.Hafidi, P.Coyle, V.Bertin, P.Lamare, V.Ciausu, A.Deschamps, Y.Hello, N.Lo Bue, G.Marinaro, A.Capone, J.J.Dañobeitia, P.Favali, M.Cannat, L. Coppola, G. Riccobene, L.Beranzoli, E.Richard, L.Vincent, A.Dolle, N.Bhairy, D.Malengros.

\section{References}

[1] G. Riccobene and NEMO Collaboration, Nuclear Instruments \& Methods 604, 149 (2009)

[2] P. Malanotte-Rizzoli et al., Progress in oceanography 39 (1997) 153. [3] C. Millot and I. TaupierLetage. Springer Handbook of Environmental Chemistry, 29 (2005)

[4] B. Manca et al., Clim. Res. 31, 239 (2006).

[5] P. Favali et al., IEEE Journal of Oceanic Engineering 38/2, 358 (2013).

[6] G. Giovanetti et al., Remote Sens. 8, 298 (2016)

[7] W. Roether W. et al., Science (Abstracts) 271, 333 (1996)

[8] Klein B. et al., Deep Sea Research Part I: Oceanographic Research Papers 46, 371 (1999)

[9] G. Pavan, O. Adam and T. Len, Applied Acoustics 71, 991 (2009)

[10] Nemo collaboration. arXiv:0804.2913 (2008)

[11] P. Coyle and the KM3NeT Collaboration, J. Phys., Conf. Ser. 888, 012024 (2017)

[12] ANTARES collaboration, Adrián-Martínez et al. Journal of Instrumentation 7 (2012).

[13] C. Tamburini et al., PLoS One 8 (7) e67523 (2013).

[14] P. Testor, A. Bosse, S. Houpert et al., Journ. of Geophysical Research:Oceans 123,1745 (2018).

[15] F. Whitney, H. Freeland, M. Robert, Prog. Oceanogr.75, 179 (2007). 